\title{
Maternal ve Fetal Sağlık İçin Büyük Tehlike: Maternal Obezite
}

\section{Great Risk For Maternal And Fetal Health: Maternal Obesity}

\author{
Büşra Demirer ${ }^{*}$, Hülya Yardımcı² \\ ${ }^{1}$ Karabük Üniversitesi Sağlık Bilimleri Fakültesi Beslenme ve Diyetetik Bölümü, Araştırma Görevlisi, Karabük, \\ Türkiye \\ ${ }^{2}$ Ankara Üniversitesi Sağlık Bilimleri Fakültesi Beslenme ve Diyetetik Bölümü, Doçent Doktor, Ankara, Türkiye \\ e-posta: busrademirer1@gmail.com, hulyardimci@gmail.com \\ ORCID: 0000-0003-1945-0485 \\ ORCID: 0000-0002-2664-4176 \\ *Sorumlu yazar/Corresponding author: Büşra Demirer ${ }^{1}$ \\ Gönderim tarihi/Received:05.02.2020 \\ Kabul tarihi/Accepted:01.06.2020 \\ DOI: $10.34087 /$ cbusbed.685203
}

\begin{abstract}
Öz
Maternal obezite, dünya çapında prevalansı gittikçe artan patolojik bir durumdur. Maternal, fetal-neonatal sağlığı olumsuz etkilemektedir. Gestasyonel diyabet, hipertansiyon, preeklampsi, düşük riski, enfeksiyonlar en sık karşılaşılan maternal komplikasyonlar iken, preterm doğum, makrozomi, konjenital anomaliler, fetal ve neonatal mortalite en sık karşılaşılan fetal komplikasyonlardandır. Maternal obezite ayrıca erken çocukluk dönemi sorunlarına ve uzun süreli sağlı problemlerine de yol açabilmektedir. Maternal obezitenin neden olduğu komplikasyonlar göz önüne alındığında, tedavi yöntemlerinin geliştirilmesinin önemi ortaya çıkmaktadır. Bu konuda öncelikle gebelik öncesi kadının normal ağırlığına getirilip gebe kalması oldukça önemlidir. Prekonsepsiyonel dönemde kadınlara obezitenin olası sonuçları hakkında bilgilendirme yapılmalıdır. İlk prenatal muayeneden itibaren düzenli ağırlık izlemi yapılmalıdır. Uluslararası otoriteler tarafından belirlenmiş ağırlık kazanım miktarlarına dikkat edilmelidir. Sağlıklı bir gebelik süreci için gerekli taramaların yapılması sağlanmalıdır. İlk muayeneden itibaren bireysel olarak hazırlanmış beslenme ve fiziksel aktivite programlarına uyulmalıdır. Bu derleme çalışmasında günümüzde prevalansı oldukça yüksek olan maternal obezitenin olası maternal ve fetal komplikasyonlarının, emzirme dönemine etkilerinin güncel bilgiler eşliğinde paylaşılması amaçlanmıştır.
\end{abstract}

Anahtar Kelimeler: beslenme, fetal sağlık, maternal sağlık, obezite

\begin{abstract}
Maternal obesity is an increasingly prevalent pathological condition worldwide. It affects negatively maternal, fetalneonatal health. Gestational diabetes, hypertension, preeclampsia, abortion risk, infections are the most common maternal complications, while preterm delivery, macrosomia, congenital anomalies, fetal and neonatal mortality are the most common fetal complications. Maternal obesity can also lead to early childhood problems and long-term health problems. Considering the complications caused by maternal obesity, the importance of developing treatment methods becomes apparent. In this regard, it is very important to bring the woman to normal weight and conceive before pregnancy. In the preconceptional period, women should be informed about the possible consequences of obesity. Regular weight monitoring should be carried out from the first prenatal examination. Attention should be paid to the weight gain amounts determined by the international authorities. Necessary screening should be provided for a healthy pregnancy process. Nutrition and physical activity programs prepared individually should be followed from the first examination. In this review study, it is aimed to share the possible maternal and fetal complications of maternal obesity, which has a high prevalence today, and the effects of breastfeeding, with current information.
\end{abstract}

Keywords: Fetal health, maternal health, nutrition, obesity 


\section{Giriş}

Gebelik boyunca ağırlık kazanımının izlenmesi önem taşımaktadır. Çünkü gebelik dönemi vücut ağırlığı değişimlerinin sık yaşandığı bir dönemdir. $\mathrm{Bu}$ dönemdeki ağırlık kazanımı ya da ağırlık kaybı maternal ve fetal sağlık sorunlarına yol açabilmektedir. Gebelik dönemi boyunca kazanılacak ağırlık birçok faktöre bağlı olarak değişsebilmektedir. Bunlardan bazıları; gebelik öncesi vücut ağırlığı ve beden kitle indeksi (BKİ), yaş, parite, etnik orijin, sosyoekonomik durum, fiziksel aktivitedir. Gebelik döneminde ağırlık kazanımı konusunda çeşitli otoriteler tarafindan bir kategorizasyon planlanmıştır. Amerikan Tıp Enstitüsü (IOM) ve Amerikan Jinekoloji ve Obstetrik Derneği (ACOG) prenatal vücut ağırlığı kazanımında gebelik öncesi BKİ'nin temel alınması gerektiğini belirtmektedir (Tablo 1) $[1,2]$.

Tablo 1. IOM ve ACOG prenatal ağırlık kazanımı önerileri

\begin{tabular}{|l|l|l|l|}
\hline $\begin{array}{l}\text { Obezite Sınıflaması } \\
\text { (NIH*) }\end{array}$ & $\begin{array}{l}\text { Gebelik Öncesi BKI } \\
\left(\mathbf{k g} / \mathbf{m}^{2}\right)\end{array}$ & $\begin{array}{l}\text { Önerilen Ağılık } \\
\text { Kazanımı (kg) (IOM) }\end{array}$ & $\begin{array}{l}\text { Önerilen Ağırlık } \\
\text { Kazanımı (kg) (ACOG) }\end{array}$ \\
\hline Zayıf & $<18.5$ & $13-18$ & $12,5-18$ \\
\hline Normal & $18,5-24,9$ & $11,5-16$ & $11,5-16$ \\
\hline Hafif Şişman & $25,0-29,9$ & $7-11,5$ & $7-11,5$ \\
\hline Obez & $\geq 30,0$ & $5-9$ & $\leq 7$ \\
\hline
\end{tabular}

*NIH: National Institutes of Health

Önerilen prenatal ağırlık kazanımları gebelik öncesi BKI temel alınarak belirlenmiş olsa da bireysel ve çevresel birçok faktöre bağlı olarak ağırlık kazanımının değişebileceği unutulmamalıdır. Yapılan bir çalışmada; 926 gebe kadın çalışmaya dahil edilmiş ve vücut ağırlık kazanımları izlenmiştir. Çalışma sonunda gebelerin \%22,6'sının IOM'un önerdiği vücut ağırlığından daha azını, \%50,0'ının ise önerilenden daha fazlasını kazandığg1 gözlenmiştir [3].

Fetal gelişimin devamlılığı ve sağlıklı bir doğum için önerilen vücut ağırlığı kazanımı sağlanmalıdır [4]. Ancak yapılan çalışmalarda hafif şişman ve/veya obez kadınlarda önerilenden daha az ağırlık kazanımının fetal gelişime olumsuz bir katkısının olmadığı gözlenmiştir. Bu sebeple hafif şişman/obez gebelerde önerilenden daha az ağırlık kazanmış ancak herhangi bir fetal sorun yaşanmamış ise gebeyi daha fazla ağırlık kazandırmaya yönlendirmek maternal ve fetal sonuçlar açısından bir iyileşme getirmeyeceği için gerekli değildir [4,5]. Ayrıca çalışma sonuçlarına göre IOM'un önerdiği değerlerin altında ağırlık kazanmış obez ve hafif şişman gebelerde maternal ve fetal herhangi bir komplikasyon gözlenmemiş, bebeklerin doğum ağırlıklarının normal sınırlarda olduğu saptanmıştır. Ancak maternal ve fetal sağlığın devamlılığı ve geliştirilmesi için her zaman en sağlıklı olan gerekli vücut ağırlığının kazanılmasıdır [5]. Bu derleme çalışma maternal obezitenin maternal ve fetal olası komplikasyonlarını ve emzirmeye etkilerini güncel bilgiler eşliğinde paylaşmak amacıyla yazılmıştır.

\section{Maternal Obezite}

Gebelik hem fizyolojik hem psikolojik birçok değișimin yaşandığı bir dönemdir. Bu dönemde yaşanılan önemli fizyolojik değişimlerden biri ise vücut ağırlığı artışıdır. $\mathrm{Bu}$ fizyolojik olarak gelişen yağ depolanması, plazma hacminin artmas1, toplam su hacminin artması ve konsepsus bileşenleri sebebiyledir. Gebelik döneminde gelişen obezite birçok komplikasyonla ilişkili olduğu için yüksek riskli bir durum olarak kabul edilmektedir [6]. Amerika'da yapılan bir çalışmada 2011 yılından 2015 yılına kadar geçen 4 yılda maternal obezite prevelansının $\% 8$ arttığını göstermektedir [7]. İzlanda'daki obez gebe prevelansinın 2005-2014 arasinda \%25,9'dan \%27,7'ye çıktığı bildirilmektedir [8]. Kanada'da yapılan geriye dönük bir kohort çalışmasına göre, gebelerin \%22'si obez bulunmuştur. Dünya çapında prevelansının belirlenmesi oldukça güç olmakla birlikte gittikçe yaygınlığının arttığı düşünülmektedir [9].

Gebe gebelik öncesi obez ise antenatal dönemde görülen fizyolojik değişiklikler farklılık gösterebilmektedir. Kardiyak outputtaki artış normal gebeliklerde görülebilirken obezite durumu şiddetlendirebilir. Benzer şekilde obezite kardiyak hipertrofi şiddetini artırır ve miyokardiyal dilatasyona sebep olur [10]. Gebelikteki gastrik reflü durumu ise obezite durumunda artmış intraabdominal basınç etkisi ile şiddetlenmektedir. Obez gebelerde mide boşalma zamanı uzamıştır. Sonuç olarak, gebelik ile obezite birleştiğinde gastrointestinal sistem yetersizlikleri ve aspirasyon riski de artmaktadir. Maternal obezite durumunda en az etkilenen sistem solunum sistemidir. Çünkü obezite, kadınların vital volümünü azaltır fakat gebelik bunu arttırır ve bazı solunum güçlüklerini ortadan kaldırabilir [11].

\subsection{Maternal Obezitenin Maternal Komplikasyonlart}

2.1.1. Gestasyonel Diabetes Mellitus (GDM)

GDM gebelik sırasında ortaya çıkan glikoz intoleransıdır. Obezite ise glisemik kontrolün sağlanmasının güçleşmesine, hiperglisemiye yatkınlığa, insülin direnci gelişme riskinin artmasına ve subklinik kardiyometabolik fonksiyon bozukluğuna sebep olabilmektedir. Gebelik öncesi obez olan ya da gebelikte aşırı ağırlı kazanan gebelerde karbonhidrat metabolizmasının bozulması normal ağırlıktaki gebelere göre fazladır bu da GDM gelişim riskini artırır [12]. Yapılan bir çalışmada obez gebelerde (BKI $>30 \mathrm{~kg} / \mathrm{m} 2)$ GDM ve gebelik hipertansiyonu gelişme riski normal BKI'ye sahip gebelere göre fazla bulunmuştur [13]. GDM, çoğunlukla doğumdan sonra düzelebilen bir durum olsa da gebeliğe obez başlayan ve gebelik 
sırasında ağırlık kazanımı fazla olan kadınlarda tip-2 diyabete dönüşme riski yüksek olan bir patolojidir. Yapılan bir çalışmada GDM gelişen kadınların \%10'undan fazlasında doğumdan sonra tip-2 diyabet geliştiği; 10 yıllık izlem sonrasında ise \%30-70'inde tip2 diyabet geliştiği gözlenmiştir [14]. Yapılan bir başka çalışmada GDM olma durumuna göre risk etmenlerinin dağılımına bakılmış ve gebelik boyunca önerilenden fazla ağırlık artışı ile anlamlı bir ilişki bulunmuştur [15]. Koruyucu önlemlerin alınabilmesi ve GDM'nin tedavi edilebilmesinde taramaların rolü büyük önem taşımaktadır. Bu nedenle GDM taraması risk faktörlerini temel almalı ve evrensel olmalıdır. GDM'nin erken tanısı, oluşabilecek fetal ve neonatal komplikasyonları azaltmak için ön koşuldur. Bu konuda ulusal ve uluslararasi otoriteler tarafindan tarama stratejileri geliştirilmiştir. Amerikan Diyabet Derneği (ADA) risk olsun olmasin tüm gebelerde 24-28. haftalarda GDM araştırmasının yapılması gerektiği bildirmiştir [16].

GDM'de tedavinin temel amac1; normoglisemiyi sağlamak ve fetal ve maternal mortalite ve morbiditeyi azaltmaktır. ADA tarafindan yayınlanan rehberde tam kan glikozu hedefleri olarak;

Açlik $<95 \mathrm{mg} / \mathrm{dl}$

1. saat $<140 \mathrm{mg} / \mathrm{dl}$
2. saat $<120 \mathrm{mg} / \mathrm{dl}$ belirlenmiştir.

GDM tedavisinde insülin/oral antidiyabetik ilaçlar ve tıbbi beslenme tedavisi ile fiziksel aktivite kullanılabilmektedir. Hastanın fizyolojik durumuna ve laboratuvar bulgularına göre tedavi stratejisi değişebilmektedir [16].

\subsubsection{Gebelik Hipertansiyonu ve Preeklampsi}

Gebelik hipertansiyonu, gebelik öncesi herhangi bir hipertansiyon durumu olmadan gebelik döneminde 6 saat ara ile elde edilen kan basınçlarının $\geq 140 / 90 \mathrm{mmHg}$ olmasıdır. Gebelik hipertansiyonu her 100 gebeden 710'unda karşılaşılabilen ancak etiyolojisi hala anlaşılamamış bir patolojidir. Gebelikte maternal ve prenatal mortaliteden ciddi oranda sorumludur. Amerikan Kadın Hastalıkları ve Doğum Enstitüsünün yayınladığı rehberde maternal obezitenin gestasyonel hipertansiyon için ciddi bir risk faktörü olduğu belirtilmiştir [17].

Preeklampsi ise gebelik hipertansiyonu, proteinüri ve ödem ile karakterize bir patolojidir. Tüm gebeliklerde ortalama \%6-8 oranında görülebilmektedir. Obezite preeklampsi için komplike bir risk faktörüdür (Şekil 1) [18].

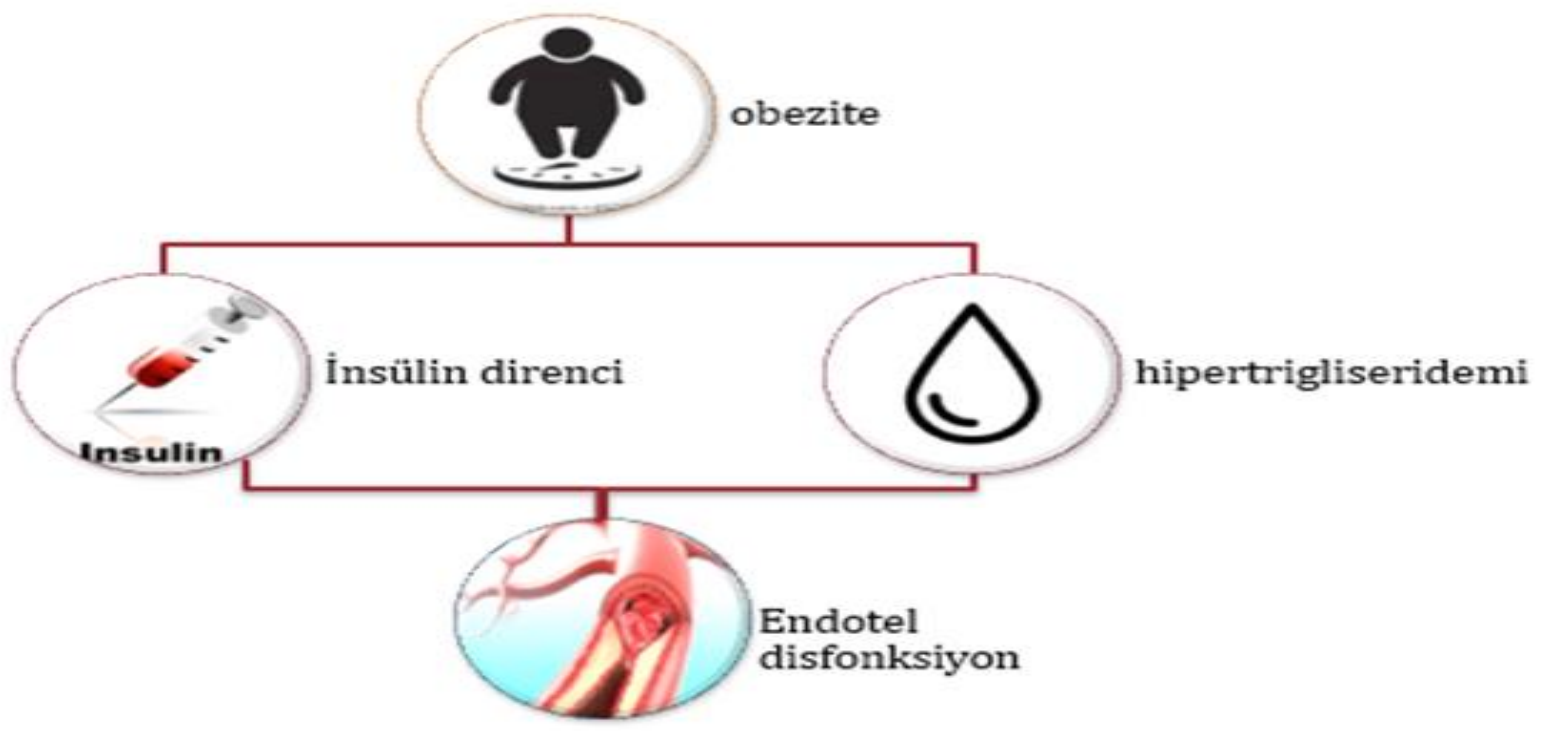

Şekil 1. Obezitenin endotel fonksiyona etkisi

Yapılan bir çalışmada preeklampsi riski normal ağırlığa sahip gebelere göre 3 kat fazla bulunmuştur [19]. Bir başka çalışmada gebelikte BKİ'nin her bir birim artışında preeklampsi riskinde $\% 8$ oranında artış bulunmuştur [20]. Bir diğer çalışmada 8176 gebe dahil edilmiş ve obez bireylerde preeklampsi insidansının 2 kat fazla olduğu gösterilmiştir [21]. Bir başka çalışmada obez kadınlarda adipositokinlerin preeklampsi patogenezinde rol alabileceği düşünülmüştür. Çalışma sonucunda obez gebelerde ilk trimesterda düşük serum adiponektin ve yüksek leptin konsantrasyonları olduğu gözlenmiştir. Bu durum, adipositokin regülasyonunun şiddetli obeziteye uyum sağlayamamasının preeklampsi patogenezinde rol oynayabileceğini göstermektedir [22].

\subsubsection{Enfeksiyonlar}

Gebelikte en sık rastlanılan enfeksiyonlar üriner sistem enfeksiyonlarıdır. $\mathrm{Bu}$ durumun en önemli sebebi ise gebelikteki hormonal değişiklikler ve mekanik baskılardır. Obez gebeler intrapartum dönemde üriner ve genital sistem enfeksiyonları yönünden riskli gruptur [23]. Maternal obezitenin yol açtığı komplikasyonların incelendiği bir çalışmada üriner enfeksiyonlar, göğüs enfeksiyonları ve genital bölge enfeksiyonlarının obez gebelerde normal ağırlıktaki gebelere göre 7,25 kat daha 
fazla görüldüğü saptanmıştır [24]. Maternal obezitenin makrofaj düzeylerine etkisinin incelendiği bir çalışmada, obez gebelerde decidua parietaliste düşük makrofaj düzeyleri saptanmıştır. Ancak makrofaj düzeylerine obezitenin etkisini anlayabilmek için çok sayıda çalışmaya daha ihtiyaç olduğu düşünülmektedir [25].

\subsubsection{Sezaryen Doğum}

Yapılan çalışmalarda obez kadınlarda doğum eylemi ile ilgili sorunları normal ağırlıktaki kadınlara göre daha fazla görüldüğü gözlenmiştir. Yapılan bir çalışmada 16609 gebe incelenmiş ve maternal BKİ'nin artması ile normal doğum şansının azaldığı gösterilmiştir. $\mathrm{Bu}$ durumun sebebi ise obezlerde maternal pelviste yumuşak doku miktarının artması ile vajinal doğumun mümkün olmaması olarak gösterilmiştir. Ayrıca sezaryen doğuma bağlı komplikasyonların da obez gebelerde daha fazla olduğu bildirilmiştir [26]. Sezaryen doğum hem sağlık harcamalarını artırmakta hem de anne bebek sağlığını olumsuz etkileyebilmektedir. Ayrıca sezaryen doğum yapan kadınların anestezi komplikasyonları, enfeksiyonlar hastanede kalma süresinin uzaması gibi olumsuzluklarla karşılaşabilmektedir. Bunun yanında obez gebelerde sezaryen doğum sonrası yara enfeksiyonu, genital ve üriner sistem enfeksiyonu, endometritis, postpartum hemoraji ve anemi gibi patolojilere rastlanmaktadır. Yapılan bir çalışmada 3. derece obez gebelerde sezaryen sonrası komplikasyonlar incelenmiş ve en sik görülen komplikasyonlar; pfannenstiel cilt insizyonları $(\% 75,6)$, deri alt dokusunun kapanmaması $(\% 65,4)$, basınçlı pansuman kullanımı $(\% 65)$ ve tromboprofilaksi $(\% 71,8)$ olarak belirlenmiştir [27,28].

\subsection{Maternal Obezitenin Fetal Komplikasyonları}

\subsubsection{Konjenital Anomaliler}

ACOG tarafindan yayınlanan kılavuzda maternal obezitenin karın duvarı defektleri, kalp defektleri ve birçok konjenital anomali ile ilişkili olduğu ayrıca obez gebelerde nöral tüp defekti (NTD), spina bifida, kardiyovasküler, orofasyal ve ekstremite redüksiyon anomalilerinin normal vücut ağırlığına sahip popülasyona oranla 2 kat daha fazla olduğu bildirilmiştir [29]. Yakın tarihli bir çalışmada obez gebelerde kardiyovasküler, ventriküler septum anomalilerinin yaklaşık olarak 1,3 kat; yarık damak ve dudak anomalilerinin ise 1,2 kat daha fazla görüldüğü bildirilmiştir [30]. İsveç'te yapılan popülasyon temelli bir kohort çalışmasında ise maternal obezite ile doğumsal kalp defektleri arasında anlamlı bir ilişki bulunmuştur. Yapılan çalışmalarda konjenital anomalilerin etiyolojisi tam olarak anlaşılamamış olsa da sebebinin, obezite ile artmış trigliserit, insülin, ürik asit ve kronik hipoksinin doğumdaki bozukluklardan sorumlu olabileceği düşünülmektedir [31]. NTD ile yapılan çalışmalarda ise maternal obezite ile kronik hipoksi, artan trigliserit, ürik asit, östrojen ve insülin düzeyi gibi maternal metabolik bozukluklar ile folik asit emiliminin yetersizliğine yol açacağı dolayısıyla embriyoya folik asit ulaşımının azalacağı düşünülmektedir [32]. Yapılan çalışmalarda maternal BKİ değerinde her $1 \mathrm{~kg} / \mathrm{m} 2$ artışın NTD riskini $\% 7$ arttırdığı bildirilmiştir. Bunların dışında diğer önemli konu ise obez gebelerde ultrason ile anomalilerin belirlenmesinin güç olmasıdır. ACOG'un yayınladığı kılavuzda normal ağırlıktaki gebelerde detaylı ultrason ile anomali tespiti oranı $\% 97$ iken obez gebelerde bu oranın \%75 olduğu bildirilmiştir [2]. Önlenebilir/tedavi edilebilir anomalilerin artmış abdominal yağlanma sebebi ile tespit edilemeyeceğine dolayısıyla bebeklerde konjenital anormallik prevelansının arttığı düşünülmektedir. Birçok çalışma tarafından bu durumun desteklenmesine rağmen Avustralya, Yeni Zelenda ve Birleşik Krallık kılavuzları haricinde uluslararası otoriteler tarafından obez gebeler için folik asit takviye önerileri yayınlanmamıştır [32,33].

\subsubsection{Makrozomi}

Maternal BKİ ile doğum ağırlığı arasında bir ilişki bulunmaktadır. Çünkü obezite maternal insülin direnci ve hiperinsülinemiye neden olmaktadır. İnsülin direnci ile plazma trigliserit düzeyi de yükselmektedir. Plasental lipazlar, fetüse serbest yağ asitleri ve trigliserit geçişini sağlamakta ve enerji deposu artmaktadır. Maternal glikoz serbestce plasentadan geçmekte fakat maternal insülin geçememektedir. Artan glikoza karşı fetal pankreasta daha fazla insülin üretilmekte ve fetal hormonlar ile büyüme ve adipozite artmaktadır. Dolayısıyla fetüs erken olgunlaşmakta ve doğum ağırlığı normalin üzerinde olmaktadır [34]. Makrozomik bebeklerde ayrıca operatif doğum, doğum travması, perinatal asfiksi ve yenidoğan ünitesine alınma riski daha fazla olmaktadır. Maternal obezite maternal diyabet ile birlikte görüldüğünde ise metabolik ve respiratuvar komplikasyon riskinin artacağ 1 bildirilmiştir. Yapılan bir metaanalizde 16 çalışma sonuçları derlenmiştir. Sonuç olarak maternal obezite durumun makrozomi riskinin tüm etkileyici faktörler ayarlandığında 1,67 kat fazla olduğu belirlenmiştir [35].

\subsubsection{Fetal ve neonatal mortalite}

Maternal obezite ile fetal, neonatal mortalite arasında ilişki bulunmaktadır. Obez kadınlarda fetal mortalite riskini 2-4 kat fazla olduğu bildirilmiştir. Ayrıca neonatal mortalitelerin büyük bir kısmının sebebinin obezite ile ilişkili doğum travmaları olduğu bildirilmiştir. Yapılan bir metaanalizde maternal BKİ'deki her 5 birimlik artışın fetal mortalite risk 1,21 kat; neonatal mortalite riskini ise 1,15 kat artırdığ 1 saptamıştır. Obezite ile fetal mortalite riskinin artmasının hiperinsülinemik bir durumun fetal büyümeyi hızlandırdığı dolayısıyla fetal pankreas yetersizliği oluşturabileceği, obezitenin fetal hipoksi riskini artıracağı düşünülmektedir [34,36].

\subsection{Maternal Obezitenin Emzirmeye Etkisi}

Gebelik öncesi obezite ya da gebelikte aşırı ağırlık kazanımı sonucu laktogenezin gecikmesi hormonal kaynaklıdır. Obezitenin progesteron düzeylerinde artışa neden olması ve yüksek progesteron düzeylerinin süt yapımında gerekli olan prolaktini baskılaması sonucu obez olan kadınların emzirmeye başlama süresi uzamaktadır [37]. Yapılan bir çalışmada gebelik öncesi $\mathrm{BKI}>26 \mathrm{~kg} / \mathrm{m} 2$ olan bireylerde gebelik öncesi normal ağırlıkta olan bireylere göre doğumdan sonra ilk 48 saatte prolaktin düzeylerinin daha düşük olduğu, laktogenezin gecikmesine bağlı olarak emzirmeye daha geç başlandığ belirtilmiştir. Ayrıca maternal obeziteye eşlik eden GDM 
ile insülin direnci laktasyonun gecikmesine sebep olabilmektedir [38]. GDM'li ve insülin tedavisi alan gebelerde yapılan bir çalışmada doğum sonrası laktasyonun gecikme riskinin GDM olmayan kadınlara göre 3,1 kat yüksek olduğu saptanmıştır. Ancak bunun için olası mekanizma hala anlaşılamamıştır [39]. Bunun yanında sezaryen doğum yapan kadınların oksitosin düzeylerinin vajinal doğum yapanlara göre düşük olması laktasyonun geç başlamasına neden olmaktadır. Obezite de vajinal doğum olasılığını azalttığı için laktasyonun gecikmesi için komplike bir risk faktörü olmaktadır. Gebelik süresince obez olan annelerin doğum sonrası yaşadıkları komplikasyonlar, büyük gögüslü olmaları nedeniyle emzirme işleminde zorlanmaları, sosyodemografik ve psikolojik faktörler ile azalan emzirme süresi ilișkilendirilmektedir [40].

\subsection{Maternal Obezitenin Yönetimi}

Maternal obezitenin yol açabileceği komplikasyonlar göz önüne alındığında, kadının gebelik öncesi vücut ağırlığını olması gereken düzeye getirmesi ve bu şekilde gebe kalması oluşabilecek komplikasyonları azaltmada oldukça önemlidir. Yapılan çalışmalarda prekonsepsiyonel dönemde \%5'lik ağırlık kaybının obeziteye eşlik eden patolojilerde azalmaya sebep olduğu bildirilmiştir [41]. Maternal obezite yönetimine yaklaşım multidisipliner ve bütüncül olmalıdır. Prekonsepsiyonel, prenatal, intrapartum ve postpartum dönemlerde ayrı ayrı obezite değerlendirmesi yapılmalıdır. Prekonsepsiyonel danışmanlık kadını maternal obeziteyle ilişkili sağlık riskleri ve gebelik öncesi normal ağırlığa ulaşmanın olası yararları hakkında eğitmek için çok önemlidir [41]. İlk prenatal muayenede $\mathrm{BKI}>30 \mathrm{~kg} / \mathrm{m} 2$ olan kadınlar, gebelik süresince aşırı ağırlık kazanımı, obezitenin riskleri ve spontan abortus belirtileri hakkında eğitilmeli ve ağırlık kazanım aralığı belirlenip, gebelik boyunca dikkatle izlenmelidir [42]. ACOG gebelik boyunca herhangi bir komplikasyon yoksa haftanın çoğu günü 30 dakikalık orta dereceli egzersizi önermektedir [2]. Fiziksel aktivitenin yanında gestasyonel ağırlık kazanımının en önemli prediktörlerinden birisi beslenmedir. Yapılan bir metaanalizde yalnızca diyet ve yalnızca fiziksel aktivite alan gebelere göre diyet ve fiziksel aktivite programını beraber yürüten gebelerde aşırı ağırlık kazanımının $\% 20$ azaldığ 1 görülmüştür. Ayrica obez gebelerde diyet ve fiziksel aktivite alan grupta makrozomi oranının \%15 azaldığ1 gözlenmiştir [2]. Sağlıklı bir beslenme programının ve Çizelge 1'de gösterilen ağırlık kazanımlarının sağlanması maternal ve fetal sağlığı etkilemektedir. Gelişmiş ülkelerdeki gebelerin beslenme programlarının incelendiği bir çalışmada gebelerin diyet uygulamaları ve makro besin ögeleri alımları arasında ciddi bir uyumsuzluk olduğu görülmüş̧ür [43]. Ulusal ve uluslararası otoriteler tarafından gebe kadınlar için beslenme önerileri yer alıyorken gebelik öncesi BKİ'ye göre bir sınıflandırma yapılıp ayrı öneriler bildirilmemiştir. Dolayısıyla maternal obezitede beslenme programına yönelik kanıta dayalı önerilerde yetersizlik bulunmaktadır [44]. Gebelerin beslenme şekillerinin incelendiği bir çalışmada gebeliğin erken döneminde daha fazla tatlı yemenin aşırı ağırlık kazanma olasılığını önemli ölçüde arttırdığ 1 ve gebeliğin son dönemlerinde daha fazla ağırlık kazanımı ile daha fazla yemek yeme arasında güçlü bir ilişki bulunduğu tespit edilmiştir [45]. Bir başka çalışmada IOM'un önerdiğinden daha fazla ağırlık kazanan gebelerin günlük ortalama 300 kalori daha fazla aldığı saptanmıştır. Bu kalorinin büyük kısmının hazır besinlerden geldiği belirtilmiştir [46]. Diyet müdahale çalışmasında gebelik öncesi BKI'lerine göre gruplara ayrılan gebeler gebeliğin başından itibaren düzenli diyetisyen kontrolü altına alınmıştır. Düzenli fiziksel aktivite ve fizyolojik durumlarına uygun beslenme programları verilen gebelerin daha az komplikasyon geliştirdiği bildirilmiştir [47]. Maternal obeziteden etkilenen bir diğer sistemde serum folat düzeyleridir. Yapılan çalışmalar serum folat düzeyinin obez gebelerde normal ağırlıktaki gebelere göre daha düşük olduğunu göstermektedir. Dolayısıyla sağlıklı bir gebelik süreci için obez gebelere yönelik gebeliğin erken döneminde ve prekonsepsiyonel dönemde folik asit takviyesi önerileri güncellenmelidir $[41,48]$. Tüm gebeler için önemli olan glikoregülasyonun sağlanması obez gebeler için de oldukça önemlidir. Obez gebelerde karbonhidrat metabolizmasının bozulması oldukça sık karşılaşılan bir durumdur. GDM riskini azaltmak ve erken teşhis koyabilmek için gerekli taramalar yapılmalıdır. Ayrıca artan fetal anomali riskine bağlı olarak fetal anomali ve maternal alfafetoprotein taraması maternal obezite durumunda önerilmektedir [41]. Sağlıklı bir gebelik süreci için prekonsepsiyonel dönemden başlayarak obezitenin gebeliğe ve fetüse etkilerinin anlatıldığ eğitim programlarının düzenlenmesi, diyetisyen kontrolünde bireysel beslenme programlarının hazırlanması ve düzenli fiziksel aktivitenin sağlıklı bir gebelik için gerekli olduğu unutulmamalıdır [2,41].

\section{Sonuc}

Yapılan çalışmalar obezitenin maternal ve fetal komplikasyonlar için önemli bir etken olduğunu göstermektedir. Prekonsepsiyonel dönemden postpartum döneme kadar tüm süreçlerde bireyler obez gebelik ve olası patolojik durumlar hakkında bilgilendirilmelidir. Mümkün ise prekonsepsiyonel dönemde kadının normal ağırlığına getirilip o şekilde gebe kalması sağlanmalıdır. IOM'un önerdiği gestasyonel ağırlık kazanımına göre gebelik boyunca kazanılacak ağırlık belirlenmeli ve ilk prenatal muayeneden itibaren düzenli olarak ağırlık izlemi gerçekleştirilmelidir. Ne olursa olsun gebelik ağırlık kaybı için doğru bir zaman değildir, dolayısıyla obez gebelerde enerji kısıtlaması önerilmemektedir. Mümkün ise gebelik öncesi dönemden erken gebeliğe kadar folik asit takviyesi yapılmalıdır. Fetal anomali riskine karşı tarama yapılmalıdır. Obez gebeler GDM açısından risk altında olduğundan GDM taraması yapılmalıdır. Gebelik boyunca glikoregülasyon sağlanmalıdır. İlk prenatal muayeneden itibaren bireysel beslenme ve fiziksel aktivite programları hazırlanmalı, sağlıklı beslenmenin gebelik için önemi gebeye anlatılmalıdır. Maternal obezite durumunda beslenme önerilerine yönelik kanıta dayalı çalışmalar yetersizdir. 
Dolayısıyla gebelik öncesi BKİ durumuna göre kategorize edilmiş gebeler için beslenme önerilerinin oluşturulması ve bu konuda daha fazla çalışma yapılması gereklidir.

\section{Referanslar}

1. Institute of Medicine, (IOM), Weight gain during pregnancy: Reexamining the Guidelines, Report Brief, 2010.

2. American College of Obstetricians and Gynecologists (ACOG) Obesity in pregnancy. ACOG Practice Bulletin No. 156. Obstetrics Gynecology, 2010, 126, 112-122.

3. Wang, D, Cui, K, Wu, G, Feng, F, Yu, X, Association of prepregnancy BKI, rate of gestational weight gain with pregnancy outcomes Chinese urban women, Nutrition and Metabolism, 2019 $16(1), 54$.

4. Melchor, I, Burgos, J, Del Campo, A, Aiartzaguena, A, Gutiérrez, J, Melchor, J.C, Effect of maternal obesity on pregnancy outcomes in women delivering singleton babies: a historical cohort study, Journal of Perinatal Medicine, 2019, 47(6), 625-630.

5. Okesene-Gafa, K.A.M, Li, M, Mckinlay, C.J.D, Taylor, R.S, Rush, E.C, Wall, C.R et al. Effect of antenatal dietary interventions in maternal obesity on pregnancy weight-gain and birthweight: Healthy Mums and Babies (HUMBA) randomized trial, American Journal of Obstetrics and Gynecology, 2019, 221(2), 152.

6. Hoover, E.A, Louis, J.M, Optimizing Health, Obstetrics and Gynecology Clinics of North America, 2019, 46(3), 431-440.

7.Deputy, N.P, Dub, B, Sharma, A.J, Prevelance and Trends in Prepregnancy Normal Weight-48 States, New York City and District of Columbia, 2011-2015, Weekly, 2018, 66(5152), 1402-1407.

8. Eiriksdottir, V.H, Valdimarsdottir, U.A, Asgeirsdottir, T.L Gisladottir, A, Lund, S.H, Hauksdottir, A, Smoking and obesity among pregnant women in Iceland, European Journal of Public Health, 2015, 25(4), 638-643.

9. MacInnis, N, Woolcott, C.G, McDonald, S, Kuhle, S, Population Attributable Risk Fractions of Maternal Overweight and Obesity for Adverse Perinatal Outcomes, Scientific Reports, 2016, 6, 22895

10. Shagana, J.A, Dhanraj, M, Jain, A.R, Nirosa, T, Physiological changes in pregnancy, Drug Invention Today, 2018, 10(8), 1594 1597.

11. Soma-Pillay, P, Nelson-Piercy, C, Tolppanen, H, Mebazaa A, Physiological changes in pregnancy, Cardiovascular Journal of Africa, 2016, 27(2), 89-94.

12. Munda, A, Starčič, Erjavec, M, Molan, K, Ambrožič, Avguštin, J, Žgur-Bertok, D, Pongrac, Barlovič, D, Association between prepregnancy body weight and dietary pattern with large-forgestational-age infants in gestational Diabetes, Diabetology \& Metabolic Syndrome, 2019, 11(1), 68.

13. Taşdemir, D, Karaman, E, Yıldız, A, Han, A, Obezitenin term gebelerde maternal ve fetal sonuçlara etkisi: bir olgu kontrol çalışması, IKSST Dergisi, 2015, 7(2), 73-78.

14. Kim, M.K, Hur, J, Lee, S.Y, Kim, L.Y, Park, K.S, Park, S.W et al Maternal obesity and associated risk of adverse pregnancy outcomes in women with hyperglycemia, Korean Journal Of Obstetrics Gynecology, 2011, 54(10), 591-598.

15. Gürkan, E, Dirican, E, Bülbül, N, Bilinen ve Olası Risk Faktörlerinin Birlikteliğinin Gestasyonel Diabetes Mellitus Gelişimine Etkisi, Ankara Medical Journal, 2018, 3, 382-90

16. American Diabetes Association (ADA), Standards of medical care in diabetes-2010, Diabetes Care, 2010, 33, 11-61.

17. Institute of Obstetricians and Gynaecologists (IOM), Obesity and pregnancy clinical practice Guideline 2, 2013.

18. Triebwasser, J.E, Kazzi, N.G, Davis, M.B, Kobernik, E.K, Levine, L.D, Langen, E.S, Cardiac remodeling in morbidly obese women and its association with adverse perinatal outcomes, Pregnancy Hypertension, 2019, 17, 104-108.

19. Institute of Obstetricians and Gynaecologists, Obesity and pregnancy clinical practice Guideline 3,2016.

20. Frederick, I.O, Rudra, C.B, Miller, R.S, Foster, J.C, Williams, M.A, Adult weight change, weight cycling, and prepregnancy obesity in relation to risk of preeclampsia, Epidemiology, 2008, 17, 428-434
21. Kerrigan, A, Kingdon, C, Maternal obesity and pregnancy: a retrospective study, Midwifery, 2010, 26(1), 138-46.

22. Thagaard, I.N, Hedley, P.L, Holm, J.C, Lange, T, Larsen, T, Krebs, $\mathrm{L}$ et al. Leptin and Adiponectin as markers for preeclampsia in obese pregnant women, a cohort study, Pregnancy Hypertension, 2019, 15, 78-83.

23. İnci, $M$, İnci, $M$, Davarc1, $M$, Gebelikte görülen üriner sistem enfeksiyonları ve tedavisi, Türkiye Üroloji Semineri, 2014, 2, 124-6.

24. McCall, S.J, Li, Z, Kurinczuk, J.J, Sullivan, E, Knight, M, Maternal and perinatal outcomes in pregnant women with BMI >50: An international collaborative study, PLOS ONE, 2019, 14(2), 1-11.

25. Laskewitz, A, Van, Benthem, K.L, Kieffer, T.E.C, Faas, M.M, Verkaik-Schakel, R.N, Plösch, T et al. The influence of maternal obesity on macrophage subsets in the human decidua, Cellular Immunology, 2019, 336, 75-82.

26. Melchor, I, Burgos, J, Del Campo, A, Aiartzaguena, A, Gutiérrez, J, Melchor, J.C, Effect of maternal obesity on pregnancy outcomes in women delivering singleton babies: a historical cohort study, Jornal Of Perinatal Medicine, 2019, 47(6), 625-630.

27. Sagi, Y, Snelgrove, J, Vernon, J, D’Souza, R, Maxwell, C, Wound Disruption Following Caesarean Delivery in Women With Class III Obesity: A Retrospective Observational Study, Journal of Obstetrics and Gynaecology Canada, 2019, 41(6), 798-804.

28. Haile, Z.T, Chavan, B, Teweldeberhan, A.K, Chertok, I.R.A, Francescon, J, Gestational weight gain and unplanned or emergency cesarean delivery in the United States, Women and Birth, 2019, 32(3), 263-269.

29. American College of Obstetricians and Gynecologists (ACOG), Obesity in pregnancy practice bulletin 156, Obstetrics Gynecology, 2015, 126, 112- 122.

30. Sirimi, N, Goilis, G.D, Obesity in pregnancy, Aristotle University of Thessaloniki, Greece, Hormones, 2010, 9(4), 299-306.

31. Persson, M, Razaz, N, Edstedt Bonamy, A.K, Villamor, E, Cnattingius, S, Maternal Overweight and Obesity and Risk of Congenital Heart Defects, Journal of the American College of Cardiology, 2019, 73(1), 44-53.

32. O’Malley, E, Reynolds, C, Cawley, S, Woodside, J.V, Molloy, A.M, Turner, M.J, Folate and vitamin B12 levels in early pregnancy and maternal obesity, European Journal of Obstetrics \& Gynecology and Reproductive Biology, 2018, 231, 80-84.

33. Zhang, L, Zhang, Y, Li, Z, Ren, A, Liu, J, Ye, R, Maternal periconceptional body mass index and risk for neural tube defects: results from a large cohort study in China, The Journal of MaternalFetal \& Neonatal Medicine, 2019, 2019, 1-7.

34. Avagliano, L, Mascherpa, M, Massa, V, Doi, P, Bulfamante, G.P, Fetal pancreatic Langerhans islets size in pregnancies with metabolic disorders, The Journal of Maternal-Fetal \& Neonatal Medicine, 2018, 32(21), 3589-3594.

35. Dai, R, He, X.J, Hu, C.L, Maternal pre-pregnancy obesity and the risk of macrosomia: a meta-analysis, Archives of Gynecology and Obstetrics, 2018, 297(1), 139-145.

36. Chaemsaithong, P, Leung, T.Y, Sahota, D, Cheng Y.K, Leung W.C, Lo T.K et al. Body mass index at 11-13 weeks' gestation and pregnancy complications in a Southern Chinese population: a retrospective cohort study, The Journal of Maternal-Fetal \& Neonatal Medicine, 2018, 32(12), 1-13.

37. Huang, Y, Ouyang, Y.Q, Redding, S.R, Maternal Prepregnancy Body Mass Index, Gestational Weight Gain, and Cessation of Breastfeeding: A Systematic Review and Meta-Analysis, Breastfeeding Medicine, 2019, 14 (6), 366-374.

38. Rasmussen, K.M, Kjolhede, C.L, Prepregnant overweight and obesity diminish the prolactin response to suckling in the first week postpartum, Pediatrics, 2014, 113, 465-71.

39. Matias, S.R, Dewey, K.G, Quesenberry, C.P, Gunderson, E.P, Maternal prepregnancy obesity and insulin treatment during pregnancy are independently associated with delayed lactogenesis in women with recent gestational diabetes Mellitus, American Journal of Clinical Nutrition, 2014, 99, 115-21.

40. Nissen, E, Uvnäs-Moberg, K, Svensson, K, Stock, S, Widström, A.M, Winberg, J, Different patterns of oxytocin, prolactin but not 
cortisol release during breastfeeding in women delivered by caesarean section or by the vaginal route, Early Human Development, 2016, 45, 103-18.

41. Jevitt, C, Pregnancy Complicated by Obesity: Midwifery Management, Journal of Midwifery Womens Health, 2017, 54(6), 445-451.

42. Özcan, A, Töz, E, Halksever, Özvatan, S, Vural, T, Sanc1, M, Obez Gebeliklerin Yönetimi, Tepecik Eğitim ve Araştırma Hastanesi Dergisi, 2016, 26(1), 1-9

43. Blumfield, M.L, Hure, A.J, Macdonald-Wicks, L, Smith, R, Collins, C.E, Systematic review andmeta-analysis of energy andmacronutrient intakes during pregnancy in developed countries, Nutrition Reviews, 2012, 70, 322-36.

44. Adamo, K.B, Ferraro, Z.M, Goldfield, G, Keely, E, Stacey, D, Hadjiyannakis, S, et al. The Maternal Obesity Management (MOM) Trial Protocol: A lifestyle intervention during pregnancy to minimize downstream obesity, Contemporary Clinical Trials, 2013, 35(1), 8796

45. Olafsdottir, A.S, Skuladottir, G.V, Thorsdottir, I, Hauksson, A, Steingrimsdottir, L, Maternal diet in early and late pregnancy in relation toweight gain, International Journal of Obesity, 2006, 30, 492-9.

46. Uusitalo, U, Arkkola, T, Ovaskainen, M.L, Kronberg-Kippilä, C, Kenward, M.G, Veijola, R, et al. Unhealthy dietary patternsare associated with weight gain during pregnancy among Finnish women, Public Health Nutrition, 2009, 12, 2392-9.

47. O’Malley, E, Reynolds, C, Cawley, S, Woodside, J.V, Molloy, A.M, Turner, M.J, Folate and vitamin B12 levels in early pregnancy and maternal obesity, European Journal of Obstetrics \& Gynecology and Reproductive Biology, 2018, 231, 80-84.

48. Crowther, C.A, Hiller, J.E, Moss, J.R, McPhee, A.J, Jeffries, W.S, Robinson, J.S, Effect of treatment of gestational diabetes mellitus on pregnancy outcomes, The New England Journal of Medicine, 2005, 352, 2477-86.

http://edergi.cbu.edu.tr/ojs/index.php/cbusbed isimli yazarın CBU-SBED başlıklı eseri bu Creative Commons Alıntı-Gayriticari4.0 Uluslararası Lisansı ile lisanslanmıştır.

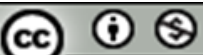

